
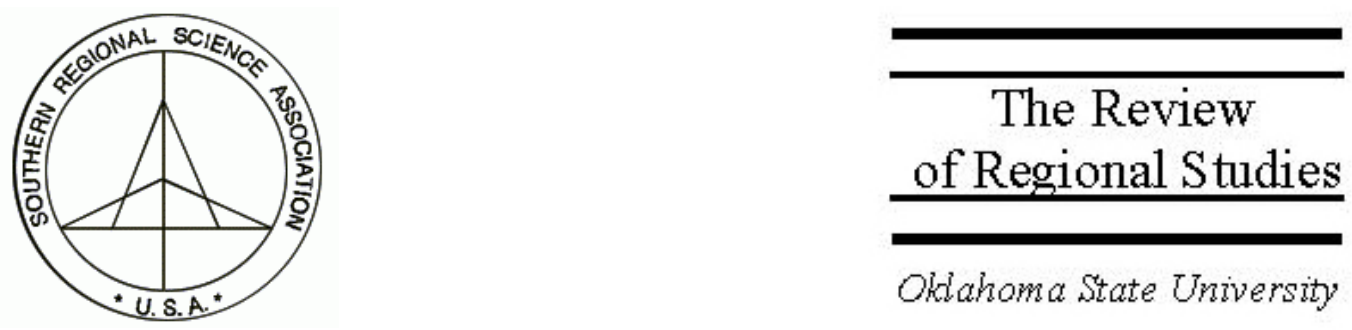

\title{
Which Matters Most to the Estimation of Efficiency and Productivity Growth in State Manufacturing: Method or Measurement?
}

\author{
Diane F. Primont \\ Department of Economics \& Finance, Southeast Missouri State University, \\ Cape Girardeau, MO 63701, e-mail: dprimont@semo.edu \\ Bruce R. Domazlicky \\ Department of Economics \& Finance, Southeast Missouri State University, \\ Cape Girardeau, MO 63701, e-mail: bdomazlicky@semo.edu
}

\begin{abstract}
The measurement of efficiency and productivity growth at the regional level requires the researcher to select among several choices for capital estimation and methodology. We look at two capital estimation techniques, by Munnell and by Garofalo and Yamarik, and two methodologies, data envelopment analysis and stochastic frontier estimation. The measurement of efficiency does not appear to be very sensitive to the choice of capital or technique. However, the measurement of productivity is sensitive to the choice of an estimation technique for a given measure of capital.
\end{abstract}

Keywords: Productivity; Data envelopment analysis; Stochastic frontier

JEL classification: D24; R11 


\section{MEASURING EFFICIENCY AND PRODUCTIVITY GROWTH}

In his 1994 survey article of regional productivity growth, Shelby Gerking lamented that the ". . . regional sources-of-growth literature is rather frustrating to read . . . because of the wide variation in reported total factor productivity growth estimates and the apparent differences in data applied" (Gerking 1994, p. 180). He goes on to ask: "How much do alternative estimates of the regional capital stock in manufacturing have on resulting total factor productivity estimates?" (Gerking 1994, p. 181). Researchers use different measures of capital due to the fact that the Bureau of Economic Analysis (BEA), the main source for regional and other data, does not publish estimates of capital stock at the regional level. Domazlicky and Weber (2003) tried to answer the question as it relates to the measurement of capital by considering five alternative estimation methods. They found considerable differences in state total factor productivity estimates, given the measure of capital that was employed.

Researchers have been interested in the measurement of productivity growth and efficiency at the regional level for several decades. Early studies, for example Hulten and Schwab (1984), concentrated on the measurement of regional productivity growth. Later studies branched into the measurement of efficiency (Williams and Moomaw 1989), the role of state infrastructure in augmenting productivity growth in manufacturing (Morrison and Schwartz 1996), explaining the differentials in regional productivity growth (Mullen and Williams 1990), accounting for air pollution in the measurement of productivity growth in state manufacturing (Färe, Grosskopf, and Pasurka 2001), and measuring regional economic convergence (Garofalo and Yamarik 2002). For all of these studies, the particular capital measure employed and the methodology that was chosen are important decisions that the researchers must make.

While the studies that Gerking reviewed primarily employed a sources-of-growth approach (see, for example, Hulten and Schwab 1984) to measure total factor productivity (TFP), more recent researchers (see, for example, Domazlicky and Weber 1997 and Weber and Domazlicky 1999) used data envelopment analysis (DEA) or a stochastic frontier approach to estimate TFP productivity growth rates.

Similar to TFP growth, regional technical efficiency can be estimated using alternative measures of capital as well as alternative methods, notably through estimating a stochastic production frontier or using DEA. Note that annual estimates of regional technical efficiency using DEA or a stochastic frontier approach are employed in constructing estimates of TFP growth.

A regional researcher who attempts to measure regional technical efficiency and/or TFP growth is now faced with a somewhat bewildering array of choices as to the method to employ as well as the capital measure to use. The perpetual inventory method to measure capital stock employed by Hulten and Schwab (1984), for example, may be the preferred approach; however, gaps in data availability in 1979-1981 make it impossible to use this approach after that period. Aaberg (1973) offers another approach to 
measuring capital using value-added and firm payroll. His approach is rarely employed today. In this paper, we consider two different measures of capital stock as developed by Munnell (1990) and by Garofalo and Yamarik (2002). Munnell's approach is the most frequently used by researchers today, while the approach of Garofalo and Yamarik has some attractive features (see below) that make it a viable alternative to that of Munnell. In addition, we consider two methods of measuring efficiency and TFP growth: stochastic frontier and DEA. A researcher considering the measurement of capital and the methods of estimation that are employed in this paper will have a choice of four possible approaches for estimating efficiency or TFP growth. Given that the true measure of capital is unknown and that the actual levels of efficiency and TFP growth are also unknown, it may be impossible to say which are best; but it may be possible to learn how sensitive estimates are to the choice of estimation methodology or of a capital measure and therefore give some indication of the robustness of productivity growth and efficiency estimates.

The next section is a very brief discussion of the alternative approaches to measuring capital and the different methods for measuring productivity and efficiency in the manufacturing sector. In the third section, we outline the results from using the different measures and methods. In the last section, we offer some very tentative conclusions and suggestions for researchers in this area.

\section{METHODS, MEASUREMENTS, AND DATA}

\subsection{Data}

Since the BEA provides no estimates of regional capital stocks, researchers are forced to develop their own estimates. As mentioned above, because there are gaps in the data on investment in capital at the regional level, the perpetual inventory method used by Hulten and Schwab (1984) is unavailable for the period after 1981. A further complication is the switch to the North American Industrial Classification System (NAICS) starting in 1997, which means that data on manufacturing after 1996 are not compatible with data from earlier periods. The regional researcher must resort to using an allocation technique whereby the national capital stock total for the manufacturing sector is allocated among the 50 states using some reasonable method.

Munnell developed a very simple technique using the five-year Census of Manufacturing. Her method is to allocate total manufacturing capital to a state according to it's proportion of national depreciable assets as reported in the Census. Munnell uses states' proportions of assets from a given census for two years before and two years after the census to allocate the national capital stock to states. The effect of this centered approach is that a state's stock of manufacturing capital grows at the national rate for five years. The one possible drawback of this approach is the discontinuity that exists when the next census is used to allocate national capital totals. This discontinuity can lead to large jumps in the capital estimates, which could skew efficiency and TFP growth estimates, particularly for states that experience declines in capital from one census to the 
next. Several researchers have used her data (Färe, Grosskopf, and Pasurka 2001; HoltzEakin 1994; Domazlicky and Weber 1997; and Morrison and Schwartz 1996).

Garofalo and Yamarik (2002, hereafter GY) use a capital allocation technique based on regional personal income. Capital in the manufacturing sector is allocated according to a state's proportion of personal income in the sector at the national level. This method is simple to implement and has the further advantage that data are available for long periods of time. Its basic assumption is that state personal income in manufacturing should be related to the amount of capital stock employed in a state. See Domazlicky and Weber (2003) for a more detailed explanation of the two approaches to capital estimation.

The two measures of capital and two approaches will be used to estimate total factor productivity growth and efficiency. The regions of interest are the 50 states for the period 1982-1996. Extension of the estimates beyond 1996 is not possible due to the change from SIC to NAICS starting with the 1997 Census of Manufactures. The measure of output is Gross State Product (GSP) in manufacturing from the BEA Website. Manufacturing output is measured in millions of chained 1996 dollars. The second input is labor. The measure of labor is millions of person hours and is taken from the Annual Survey of Manufactures (Bureau of the Census). Non-production personnel are assumed to work 40 hours per week for 50 weeks of the year, which are then added to the hours of production workers to get total person hours. The capital estimates are calculated as indicated above and are in millions of chained 1996 dollars. Descriptive statistics for the variables included in the models are given in Table 1.

\subsection{Measurement of Technical Efficiency and Total Factor Productivity}

Measurement of efficiency draws on the work of Farrell (1957). Technical efficiency is the ability to produce maximal output with a given level of inputs. That is, technical efficiency is measured as a distance from the production frontier. We illustrate this idea in the simple case of one output $(y)$ and one input $(x)$. Figure 1 shows a decreasing returns to scale production frontier in panel (a) and a constant returns to scale production frontier in panel (b). The input-output combinations for two states are illustrated: state 1,

\section{TABLE 1}

\begin{tabular}{clrrrc}
\multicolumn{6}{c}{ Descriptive Statistics } \\
\hline Variable & \multicolumn{1}{c}{ Description } & Mean & Std. Dev. & Min. & Max. \\
\hline$Y$ & $\begin{array}{l}\text { Real State GDP in manufacturing } \\
\text { (millions of chained 1996 dollars) }\end{array}$ & $21,425.7$ & $23,241.6$ & 386.8 & $134,669.0$ \\
& $\begin{array}{l}\text { Hours worked in manufacturing } \\
\text { (millions of hours) }\end{array}$ & 745.5 & 794.2 & 14.1 & $4,243.0$ \\
$\quad$ Capital Stock (millions of chained & & & & \\
$\quad$ 1996 dollars) & & & & \\
& Munnell methodology & $27,135.5$ & $28,275.3$ & 989.9 & $136,886.0$ \\
& $\quad 27,113.3$ & $31,099.8$ & 464.9 & $168,657.6$ \\
GY methodology & 750 & & & \\
number of observations & & &
\end{tabular}




\section{FIGURE 1}

\section{Input-Oriented and Output-Oriented Measures of Technical Efficiency and Returns to Scale}

(a) Decreasing Returns to Scale

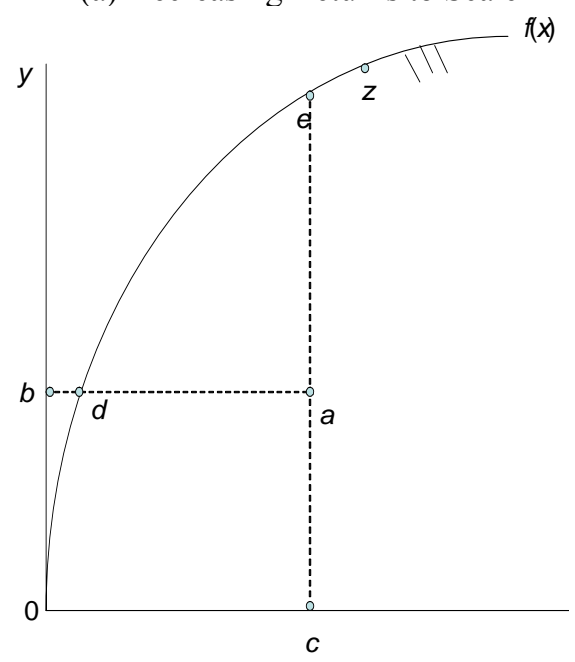

(b) Constant Returns to Scale

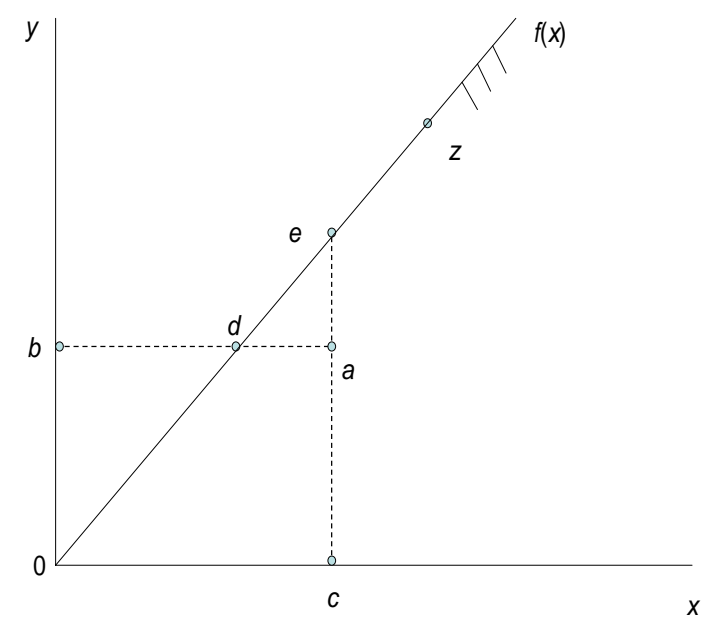

which is represented by point $a$, and state 2 , which is represented by point $z$. State 2 has an input-output combination that lies on the frontier. Therefore, state 2 is obtaining maximal output from its given input, i.e., the state is technically efficient. Technical efficiency for state 2 is equal to 1 .

On the other hand, state 1's input-output combination is inside the frontier, so state 1 is technically inefficient. The amount of technical efficiency can be calculated in either an input orientation or an output orientation. From an input orientation, technical efficiency is measured as $b d / b a$, the ratio of minimum potential input to actual or observed input, which is an amount between 0 and 1. The closer the value is to 1 , the less inefficiency. $1-b d / b a=d a / b a$ is the proportion by which the state could reduce its inputs and still produce the same output.

From an output orientation, technical efficiency is measured as ca/ce, the ratio of actual or observed output to maximum potential output, which takes on values between 0 and 1 . The closer the value is to 1 , the less inefficiency. Thus, ca/ce $-1=\mathrm{ea} / \mathrm{ce}$ is the proportion by which output could be expanded, given the inputs.

Note that only in panel (b), under constant returns to scale, the measure of technical efficiency with an input orientation is equal to the reciprocal of technical efficiency with an output orientation, so that $d a / b a=e a / c e$. 
How performance has changed over time is measured by total factor productivity (TFP) growth. TFP describes the growth in output that is not explained by the growth in inputs. That is, TFP growth is

$$
\text { TFP growth }=\frac{y^{t+1} / x^{t+1}}{y^{t} / x^{t}},
$$

which is the ratio of average products in the two time periods. When there is more than one output or more than one input, an index number is needed to aggregate the outputs and/or inputs. For example, one could use a Fisher's Ideal index, a Tornquist index, or a Malmquist index. We use the Malmquist productivity index developed by Caves, Christensen, and Diewert (1982).

In the one output-one input case, suppose that $\left(x^{t}, y^{t}\right)$ is observed in year $t$ and $\left(x^{t+1}, y^{t+1}\right)$ is observed in year $t+1$. These observed input-output combinations along with two production frontiers, $f^{t}(x)$ in period $t$ and $f^{t+1}(x)$ in period $t+1$, are illustrated in Figure 2. Productivity growth could be measured relative to the production frontier from either period, $f^{t}(x)$ in period $t$ or $f^{t+1}(x)$ in period $t+1$. From an input orientation, using the production frontier $f^{t}(x)$ in period $t$, TFP growth is

$$
\text { TFP growth }=\frac{0 f / 0 e}{0 b / 0 d} \text {. }
$$

Similarly, using the production frontier $f^{t+1}(x)$ in period $t+1$, TFP growth is

$$
\text { TFP growth }=\frac{0 c / 0 e}{0 a / 0 d}
$$

Färe, Grosskopf, and Roos (1998) define the input-oriented Malmquist TFP index as the geometric mean of (2) and (3),

$$
\begin{aligned}
\text { Malmquist TFP growth } & =\left[\frac{0 f / 0 e}{0 b / 0 d} \frac{0 c / 0 e}{0 a / 0 d}\right]^{1 / 2} \\
= & {\left[\frac{0 c / 0 e}{0 b / 0 d}\right]\left[\frac{0 f / 0 c}{0 a / 0 b}\right]^{1 / 2} }
\end{aligned}
$$

The first expression in parenthesis on the right side of (4) measures the change in technical efficiency between periods $t$ and $t+1: 0 c / 0 e$ is the technical efficiency of observation $\left(x^{t+1}, y^{t+1}\right)$ relative to the production frontier for period $t+1$, and $0 b / 0 d$ is the technical efficiency of observation $\left(x^{t}, y^{t}\right)$ relative to the production frontier for period $t$. 


\section{FIGURE 2}

\section{Input-Oriented Measurement of TFP Growth}

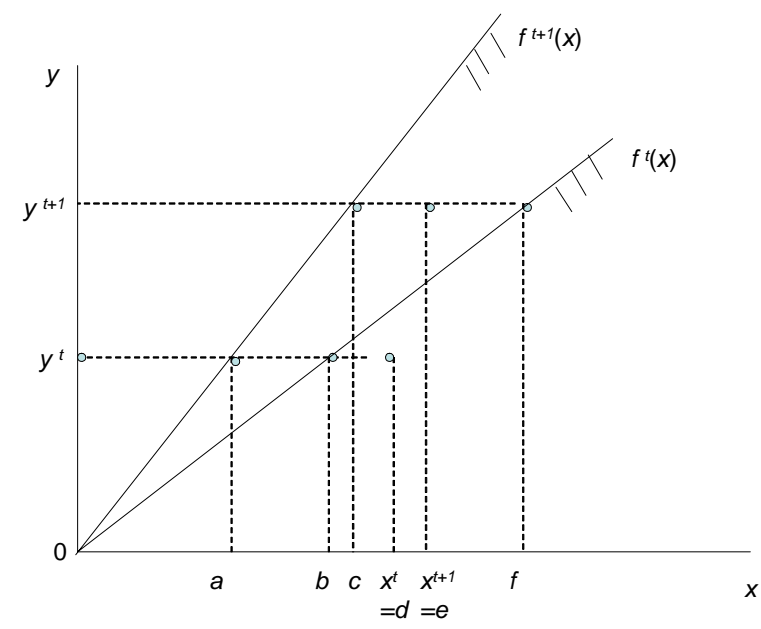

The second term on the right side of (4) measures the geometric mean of technical change, the shift in the production frontier between periods $t$ and $t+1$. $0 f / 0 \mathrm{c}$ is the horizontal shift of the production frontier at $y^{t+1}$, while $0 a / O b$ is the horizontal shift in the production frontier at $y^{t}$. That is, the Malmquist TFP index is

Malmquist TFP growth $=\Delta$ technical efficiency $\cdot$ geometric mean of technical change, where $\Delta$ is the change.

Both the measures of technical efficiency and Malmquist TFP growth require estimation of production frontiers. Two principal methods of estimating frontier functions are DEA and stochastic frontiers. The two methods differ in how the production frontier is estimated. DEA uses linear programming methods and the latter uses econometric methods to estimate the frontier.

The Malmquist index of TFP growth in (4) and (5) equals the notion of TFP growth in (1) only under constant returns to scale. (See Färe, Grosskopf, and Roos 1998, p. 137, for details.) Therefore, in our empirical work, we have imposed constant returns to scale on the production frontiers estimated for measuring both technical efficiency and Malmquist TFP growth indices using both DEA and stochastic frontiers.

\subsubsection{Data Envelopment Analysis}

DEA is one method used in this paper to estimate state efficiency in manufacturing and TFP growth. Let $x$ be a vector of the two inputs capital $(K)$ and labor $(L)$.

$$
x=(K, L)
$$


Similarly, there is one output, $y$, which is GSP in manufacturing. In addition, there are $i=1, \ldots, 50$ states. For each state then, there are two inputs and one output for each year of the sample period. Time subscripts are omitted for ease of explanation.

Constant returns to scale are assumed along with strong disposability of inputs. The latter assumption means that output is non-decreasing in inputs. DEA uses linear programming to construct the production frontier using the observations on capital, labor, and output for the 50 states. States that are located on the frontier are said to be efficient (their efficiency level is equal to 1), while states that are inside the frontier are inefficient. Inefficient states use more inputs than are necessary to produce their output. The efficiency levels of states that are not on the production frontier will be less than 1. Such states could produce the same output level with fewer resources. For example, a state with an efficiency level of 0.70 could produce the same output level using 30 percent fewer resources. The extent of the inefficiency can be measured by the efficiency score, $\lambda$, which is the ratio of minimum feasible input usage to the actual level of input usage for a given output level.

For state $i$, the Farrell input-oriented measure of technical efficiency $\left(F_{I}\right)$ under constant returns to scale $(C)$ and strong disposability of inputs $(S)$ is calculated as the solution to the linear programming problem:

$$
\begin{aligned}
& F_{I}(y, x \mid C, S)=\min _{\lambda, z} \lambda \\
& \text { s.t. } \sum_{i} z_{i} y_{i} \geq y_{i^{\prime}} \\
& \sum_{i} Z_{i} x_{i n} \leq \lambda x_{i^{\prime} n} \quad n=K, L \\
& z_{i} \geq 0 \quad i=1, \ldots, 50
\end{aligned}
$$

where the $z_{i}$ are intensity variables. The linear programming problem is solved for each state for each year of the sample period.

The technical efficiency measures are used to calculate Malmquist TFP indices for the states. Färe, Grosskopf, and Lovell (1994) show that the input-oriented Malmquist index of TFP growth can be calculated using Farrell technical efficiency measures as:

$$
\begin{aligned}
\text { Malmquist TFP growth } & =\frac{F_{I, t+1}^{t}\left(y^{t}, x^{t} \mid C, S\right)}{F_{I}^{t+1}\left(y^{t+1}, x^{t+1} \mid C, S\right)} \\
& \cdot\left[\frac{F_{I}^{t+1}\left(y^{t+1}, x^{t+1} \mid C, S\right)}{F_{I}^{t}\left(y^{t+1}, x^{t+1} \mid C, S\right)} \cdot \frac{F_{I}^{t+1}\left(y^{t}, x^{t} \mid C, S\right)}{F_{I}^{t}\left(y^{t}, x^{t} \mid C, S\right)}\right\rfloor^{1 / 2}
\end{aligned}
$$

where $F_{I}{ }^{t+1}\left(y^{t+1}, x^{t+1}\right)$ is the Farrell input-oriented measure of technical efficiency using the production frontier for period $t+1$ and the input-output vector for period $t+1$, and 
$F_{I}^{t+1}\left(y^{t}, x^{t}\right)$ is the Farrell input-oriented measure of technical efficiency using the production frontier for period $t+1$ and the input-output vector for period $t$, and so on.

As in (5), the first ratio on the right side of (7) measures the change in technical efficiency between the two periods. The second set of ratios (in brackets) is technical change measured by the geometric mean of the shifts in the frontier from periods $t$ to $t+1$. Hence, the Malmquist TFP index from periods $t$ to $t+1$ is the product of the change in technical efficiency and the geometric mean of technical change. Equations (6) and (7) are estimated for each state using the software OnFront, version 2.

\subsubsection{Stochastic Production Frontier}

Alternatively, we investigate state efficiency and productivity in manufacturing by estimating a stochastic production frontier panel data model. See, for example, Kumbhakar and Lovell (2000) or Coelli, Rao, and Battesse (1999). We assume the production frontier can be written in translog form:

$$
\begin{aligned}
\ln Y_{i t} & =\beta_{0}+\beta_{K} \ln K_{i t}+\beta_{L} \ln L_{i t}+\beta_{t} t+(1 / 2) \beta_{K K}\left(\ln K_{i t}\right)^{2} \\
& +(1 / 2) \beta_{L L}\left(\ln L_{i t}\right)^{2}+\beta_{K L} \ln K_{i t} \ln L_{i t}+(1 / 2) \beta_{t t} t^{2} \\
& +\beta_{K t} \ln K_{i t} t+\beta_{L t} \ln L_{i t} t+v_{i t}-u_{i t}
\end{aligned}
$$

where $v_{i t}$, distributed iid $N\left(0, \sigma_{v}^{2}\right)$, is the random noise component and $u_{i t}$ is the nonnegative technical efficiency component.

Note that $t$ is included as one of the regressors to capture the effects of technical change. Technical change is given by $\partial \ln Y / \partial t$.

We allow technical efficiency to be time-varying by specifying the technical efficiency component as a non-linear function of time. Specifically, we assume

$$
u_{i t}=u_{i}\{\exp (-\eta(t-T))\}
$$

where $u_{i}$ is distributed iid $N^{+}\left(\mu, \sigma_{u}^{2}\right)$. That is, $u_{i}$ is a non-negative random variable from a truncated normal distribution (Battese and Coelli 1992). The parameter $\eta$ is to be estimated. This specification allows technical efficiency to vary across states via the $u_{i} \mathrm{~s}$. Technical efficiency varies across time via $\{\exp (-\eta(t-T))\}$, which is the same for each state.

As noted earlier, Malmquist productivity indices are best estimated under constant returns to scale (Färe, Grosskopf, and Roos 1998; Coelli, Rao, and Battese 1999). Constant returns to scale implies the following parametric restrictions: 


$$
\begin{gathered}
\beta_{K}+\beta_{L}=1 \\
\beta_{K K}+\beta_{K L}=0 \\
\beta_{L L}+\beta_{K L}=0 .
\end{gathered}
$$

These restrictions are imposed by normalizing output and the labor input by the capital input. In addition, we mean-differenced the output, capital, and labor variables so that the output elasticities, calculated at the sample means, are represented by the first order terms. That is, the equation we estimate may be written as:

$$
\begin{aligned}
\ln y_{i t} & =\beta_{0}+\beta_{L} \ln l_{i t}+\beta_{t} t+(1 / 2) \beta_{L L}\left(\ln l_{i t}\right)^{2} \\
& +(1 / 2) \beta_{t t} t^{2}+\beta_{L t} \ln l_{i t} t+v_{i t}-u_{i t}
\end{aligned}
$$

where

$$
\begin{aligned}
& \ln y_{i t}=\left(\ln Y_{i t}-\text { mean } \ln Y\right)-\left(\ln K_{i t}-\text { mean } \ln K\right) \\
& \ln l_{i t}=\left(\ln L_{i t}-\text { mean } \ln L\right)-\left(\ln K_{i t}-\text { mean } \ln K\right),
\end{aligned}
$$

$t$ is a time trend, and $v_{i t}$ and $u_{i t}$ are as defined above.

The results are used to compute measures of efficiency change, technical change, and Malmquist total factor productivity indices. Technical efficiency for state $i$ in year $t, T E_{i t}$, is computed as the conditional mean (see Coelli, Rao, and Battese 1999, for computational details):

$$
T E_{i t}=E\left(\exp \left(-u_{i t}\right) \mid v_{i t}-u_{i t}\right) .
$$

That is, in the stochastic production frontier model, the deviation of an observation from the frontier consists of two parts: random error $\left(v_{i t}\right)$ and technical efficiency $\left(-u_{i t}\right)$. We observe $\left(v_{i t}-u_{i t}\right)$ but need to estimate $-u_{i t}$, the technical efficiency component. The maximum likelihood estimates of the parameters in (10) and estimates of (11) are obtained using the software FRONTIER Version 4.1 (Coelli 1996).

Technical efficiency change for state $i$ from period $t$ to period $t+1$ is given by

$$
\Delta \text { technical efficiency }_{i, t, t+1}=T E_{i, t+1} / T E_{i, t} \text {. }
$$

Technical change for the ith state from period $t$ to period $t+1$ can be calculated from the estimated parameters. The partial derivatives of the production function with respect to time periods $t$ and $t+1$ are evaluated at $\ln l_{i t}$ and $\ln l_{i t+1}$, respectively. Following Coelli, Rao, and Battese (1999), technical change is calculated as the geometric mean of the partial derivatives: 


$$
\begin{aligned}
& \text { geometric mean of technical change } e_{i, t, t+1} \\
& \qquad=\left\{\left[1+\beta_{t}+\beta_{t t} * t+\beta_{L t} * \ln l_{i t}\right] \cdot\left[1+\beta_{t}+\beta_{t t} *(t+1)+\beta_{L t} * \ln l_{i t+1}\right]\right\}^{1 / 2} .
\end{aligned}
$$

The Malmquist TFP index between period $t$ and $t+1$ is then constructed as:

$$
\begin{aligned}
& \text { Malmquist TFP growth }{ }_{i, t, t+1}=\Delta \text { technicalefficiency }_{i, t, t+1} \\
& \qquad \text { geometric mean of technical change }_{i, t, t+1}
\end{aligned}
$$

\section{EMPIRICAL RESULTS}

Parameter estimates from the constant returns to scale translog stochastic production frontier in equation (10) are contained in Table 2. The output, capital, and labor variables are in logs and are normalized by the means of each respective variable. In addition, we divide output and labor by capital. Therefore, there are five independent variables in the translog production function: normalized labor, normalized labor squared, the cross product of normalized labor and time, time, and time squared. For the GY capital measure, all parameter estimates have the expected signs and all but $\beta_{L t}$ are statistically different from zero at the 5 percent level. The coefficient on the time trend variable, $\beta_{t}$, suggests there is positive technological progress. However, the effect is non-linear since the coefficient on the square of time is negative. For the Munnell capital measure, all parameter estimates have the expected signs and all coefficients except $\beta_{L L}$ and $\beta_{L t}$ are significant at the 5 percent level, casting some doubt on the translog functional form. The parameters $\beta_{t}$ and $\beta_{t t}$ suggest positive but non-linear technical progress.

TABLE 2

Stochastic Production Frontier Parameter Estimates

\begin{tabular}{crrrrr}
\hline & \multicolumn{2}{c}{ Munnell Capital Measure } & \multicolumn{2}{c}{ GY Capital Measure } \\
\cline { 2 - 3 } \cline { 5 - 6 } Coefficient & Estimate & t-ratio & & Estimate & t-ratio \\
\hline$\beta_{0}$ & 0.2051 & 5.2688 & & 0.2384 & 5.7673 \\
$\beta_{L}$ & 0.8481 & 18.0813 & & 0.4524 & 4.0768 \\
$\beta_{t}$ & 0.0265 & 5.3303 & & 0.0236 & 4.4903 \\
$\beta_{L L}$ & -0.0152 & -0.4282 & -0.8608 & -2.9765 \\
$\beta_{L t}$ & 0.0029 & 0.9261 & -0.0136 & -1.4258 \\
$\beta_{t t}$ & -0.0006 & -2.398 & -0.0009 & -3.2380 \\
$\sigma^{2}$ & 0.0328 & 7.3798 & 0.0265 & 6.3280 \\
$\gamma$ & 0.6102 & 17.7256 & 0.5788 & 14.0130 \\
$\mu$ & 0.2832 & 7.4226 & 0.2478 & 5.6490 \\
$\eta$ & 0.0243 & 3.0026 & 0.0313 & 3.0614 \\
$\log$ likelihood & 479.160 & & 511.802 & \\
\hline
\end{tabular}


As noted earlier, the output elasticity with respect to labor is given by $\beta_{L}$, which represents labor's share of income. We calculated labor's share of income in manufacturing using the regional gross state product tables from the United States Department of Commerce Bureau of Economic Analysis as compensation of employees in manufacturing divided by nominal gross state product in manufacturing. For the period 1982-1996, labor's share of income in manufacturing averaged 0.682. We tested the null hypothesis that $\beta_{L}=0.682$ in Table 2 for both the Munnell and GY capital measures. This hypothesis could not be rejected for the Munnell capital measure ( $t$-statistic $=$ $0.354)$; however, it was rejected for the GY capital measure ( $t$-statistic $=-2.068$ ). We did not expect to be able to reject the null hypothesis for either capital measure.

We tested a number of additional hypotheses about the stochastic production function using likelihood ratio tests. Results are shown in Table 3. The first hypothesis is that the production technology could be represented by a constant returns to scale Cobb-Douglas production function $\left(\mathrm{H}_{0}: \beta_{L L}=\beta_{L t}=0\right)$. This hypothesis is rejected for the GY capital measure, indicating that the constant returns translog is preferred. However, for the Munnell capital measure, this hypothesis is not rejected. Therefore, the Munnell data could be represented by a Cobb-Douglas production function; nevertheless, it was decided to use the translog functional form for the Munnell approach. Use of the CobbDouglas production function implies that technical change is identical across states. While we might expect that technical innovation would spread quickly across states, it did not seem likely that technical change would be identical across states. The translog function is more flexible and does not impose this restriction.

TABLE 3

Hypothesis Tests

\begin{tabular}{lcrll}
\hline Null Hypothesis & Log Likelihood & $X^{2}$ statistic & \multicolumn{2}{c}{$X^{2}$ critical } \\
\hline Munnell capital measure & 477.94 & 2.44 & $X_{2,0.95}^{2}$ & 5.99 \\
(1) $\beta_{L L}=\beta_{L t}=0$ & 468.09 & 22.14 & $X_{3,0.95}^{2} 7.81$ \\
(2) $\beta_{t}=\beta_{t t}=\beta_{L t}=0$ & 291.66 & 375.24 & $X_{3,0.95}^{2 *} 7.05$ \\
(3) $\gamma=\mu=0$ & 465.47 & 27.38 & $X_{1,0.95}^{2} 3.84$ \\
(4) $\mu=0$ & 473.81 & 10.70 & $X_{1,0.95}^{2} 3.84$ \\
(5) $\eta=0$ & & & & \\
GY capital measure & 501.69 & 20.22 & $X_{2,0.95}^{2}$ & 5.99 \\
(1) $\beta_{L L}=\beta_{L t}=0$ & 509.76 & 4.08 & $X_{3,0.95}^{2} 7.81$ \\
(2) $\beta_{t}=\beta_{t t}=\beta_{L t}=0$ & 327.83 & 367.95 & $X_{3,0.95}^{2 *}$ & 7.05 \\
(3) $\gamma=\mu=0$ & 499.74 & 24.13 & $X_{1,0.95}^{2}$ & 3.84 \\
(4) $\mu=0$ & 504.08 & 15.44 & $X_{1,0.95}^{2} 3.84$ \\
(5) $\eta=0$ & & & & \\
\hline *mixed X critical value is from Kodde and Palm (1986, p. 1246) & & &
\end{tabular}


Second, we tested the hypothesis that there was no technical change over the 15-year time period $\left(\mathrm{H}_{0}: \beta_{t}=\beta_{t t}=\beta_{L t}=0\right)$. This hypothesis could not be rejected for the GY measure, but it was rejected for the Munnell measure. We would have expected some technical change over the period using both measures of capital. Nevertheless, the estimates of technical change using the GY and Munnell measures were very similar. We found that (the geometric mean of) the technical change component of the Malmquist TFP growth for the stochastic frontier approach from (13) was 2.2 percent per year for the Munnell measure and 1.7 percent per year for the GY measure.

The third hypothesis is that there is no technical inefficiency. This is a joint test of two parameters in the distribution of the technical efficiency error component. The parameter $\gamma$ is the ratio of the error variance of technical efficiency to the total error variance due to technical efficiency and random error, i.e., $\gamma=\sigma_{u}^{2} /\left(\sigma_{u}^{2}+\sigma_{v}^{2}\right)$. If $\gamma=0$ and $\mu=0$, then there is no truncated normal error component. That is, there is no technical inefficiency. This hypothesis is strongly rejected in both cases.

The fourth hypothesis is that the distribution of $u_{i}$ is better represented by a halfnormal distribution $\left(\mathrm{H}_{0}: \mu=0\right)$. We reject this hypothesis, indicating that $u_{i}$ is from a truncated normal distribution. Finally, we tested whether technical inefficiency is timeinvariant $\left(\mathrm{H}_{0}: \eta=0\right)$. This hypothesis is also rejected in both cases. Technical inefficiency varies over time. Since our estimate of $\eta$ is positive, technical efficiency is improving over time.

\subsection{State Efficiency Measurement}

The average estimates of state efficiency in manufacturing are presented in Table 4. The average estimates shown for each state were calculated as the geometric mean of the state's annual efficiency measures. For the DEA approach, a state's average technical efficiency over the years in the sample was calculated as the geometric mean of the estimated $\lambda \mathrm{s}$ from (6). For the stochastic frontier approach, the state's average technical efficiency was the geometric mean of the estimates from (11). The adjacent columns show the state's rank using each efficiency measure. The first two columns of estimates use the Munnell measure of capital, while the last two columns use the GY measure of capital. In each pair of columns, the first contains efficiency estimates derived from the stochastic production frontier model, while the latter contains efficiency estimates derived from the DEA model.

While there is a difference in the magnitude of these estimates, the estimates are strongly correlated. To determine how close the rankings of states are among the various capital measures and models, we calculated Spearman rank-order correlation coefficients, which is a non-parametric measure of correlation. A value of 1 indicates perfect correlation, while a value of 0 indicates no correlation. We also calculated Pearson's correlation coefficients, which assume that estimates come from normal distributions. For example, in the last two columns in Table 5 based on the GY capital measure, efficiency estimates 
TABLE 4

State Efficiency in Manufacturing

\begin{tabular}{|c|c|c|c|c|c|c|c|c|}
\hline \multirow[b]{2}{*}{ State } & \multicolumn{5}{|c|}{ Munnell Capital Measure } & \multicolumn{3}{|c|}{ GY Capital Measure } \\
\hline & Stochastic & Rank & DEA & Rank & Stochastic & Rank & DEA & Rank \\
\hline $\mathrm{AL}$ & 0.605 & 44 & 0.505 & 46 & 0.697 & 30 & 0.590 & 30 \\
\hline AK & 0.887 & 4 & 0.771 & 10 & 0.914 & 4 & 0.775 & 4 \\
\hline AZ & 0.628 & 41 & 0.628 & 31 & 0.598 & 49 & 0.505 & 49 \\
\hline $\mathrm{AR}$ & 0.607 & 43 & 0.560 & 44 & 0.739 & 15 & 0.629 & 14 \\
\hline $\mathrm{CA}$ & 0.691 & 23 & 0.704 & 15 & 0.635 & 44 & 0.541 & 43 \\
\hline $\mathrm{CO}$ & 0.688 & 26 & 0.639 & 25 & 0.666 & 38 & 0.558 & 38 \\
\hline $\mathrm{CT}$ & 0.700 & 20 & 0.793 & 9 & 0.625 & 45 & 0.539 & 45 \\
\hline $\mathrm{DE}$ & 0.982 & 1 & 0.853 & 1 & 0.919 & 3 & 0.798 & 2 \\
\hline FL & 0.645 & 37 & 0.658 & 23 & 0.649 & 41 & 0.540 & 44 \\
\hline GA & 0.657 & 34 & 0.604 & 36 & 0.764 & 9 & 0.650 & 9 \\
\hline HI & 0.747 & 13 & 0.630 & 29 & 0.762 & 10 & 0.645 & 11 \\
\hline ID & 0.657 & 35 & 0.568 & 43 & 0.671 & 37 & 0.564 & 37 \\
\hline $\mathrm{IL}$ & 0.660 & 33 & 0.606 & 35 & 0.642 & 42 & 0.542 & 42 \\
\hline IN & 0.688 & 25 & 0.581 & 42 & 0.683 & 35 & 0.575 & 33 \\
\hline IA & 0.728 & 15 & 0.624 & 33 & 0.743 & 14 & 0.625 & 16 \\
\hline $\mathrm{KS}$ & 0.690 & 24 & 0.638 & 26 & 0.733 & 17 & 0.615 & 20 \\
\hline KY & 0.910 & 3 & 0.770 & 11 & 0.934 & 2 & 0.785 & 3 \\
\hline LA & 0.944 & 2 & 0.843 & 2 & 0.984 & 1 & 0.879 & 1 \\
\hline ME & 0.576 & 46 & 0.485 & 47 & 0.660 & 39 & 0.554 & 39 \\
\hline MD & 0.678 & 30 & 0.594 & 39 & 0.684 & 33 & 0.576 & 32 \\
\hline MA & 0.681 & 28 & 0.796 & 8 & 0.618 & 46 & 0.526 & 46 \\
\hline MI & 0.827 & 5 & 0.717 & 14 & 0.747 & 13 & 0.649 & 10 \\
\hline $\mathrm{MN}$ & 0.735 & 14 & 0.761 & 12 & 0.684 & 32 & 0.574 & 34 \\
\hline MS & 0.570 & 48 & 0.511 & 45 & 0.734 & 16 & 0.623 & 17 \\
\hline $\mathrm{MO}$ & 0.782 & 7 & 0.804 & 6 & 0.758 & 11 & 0.640 & 12 \\
\hline MT & 0.701 & 19 & 0.595 & 38 & 0.754 & 12 & 0.629 & 13 \\
\hline $\mathrm{NE}$ & 0.648 & 36 & 0.700 & 16 & 0.718 & 21 & 0.612 & 22 \\
\hline NV & 0.693 & 21 & 0.688 & 18 & 0.730 & 19 & 0.610 & 23 \\
\hline $\mathrm{NH}$ & 0.640 & 39 & 0.729 & 13 & 0.599 & 48 & 0.509 & 48 \\
\hline NJ & 0.763 & 12 & 0.803 & 7 & 0.699 & 29 & 0.601 & 26 \\
\hline NM & 0.677 & 31 & 0.600 & 37 & 0.704 & 26 & 0.623 & 18 \\
\hline NY & 0.801 & 6 & 0.840 & 3 & 0.731 & 18 & 0.628 & 15 \\
\hline $\mathrm{NC}$ & 0.685 & 27 & 0.681 & 19 & 0.808 & 7 & 0.687 & 7 \\
\hline ND & 0.564 & 50 & 0.469 & 50 & 0.691 & 31 & 0.587 & 31 \\
\hline $\mathrm{OH}$ & 0.766 & 10 & 0.678 & 20 & 0.717 & 22 & 0.614 & 21 \\
\hline $\mathrm{OK}$ & 0.728 & 16 & 0.623 & 34 & 0.706 & 25 & 0.606 & 25 \\
\hline OR & 0.719 & 18 & 0.637 & 27 & 0.709 & 24 & 0.598 & 27 \\
\hline PA & 0.665 & 32 & 0.629 & 30 & 0.639 & 43 & 0.544 & 41 \\
\hline RI & 0.587 & 45 & 0.828 & 5 & 0.609 & 47 & 0.512 & 47 \\
\hline $\mathrm{SC}$ & 0.570 & 47 & 0.482 & 48 & 0.671 & 36 & 0.573 & 35 \\
\hline
\end{tabular}




\begin{tabular}{ccrcccccc}
\hline & & \multicolumn{1}{c}{ Munnell Capital Measure } & & \multicolumn{3}{c}{ GY Capital Measure } \\
State & Stochastic & Rank & DEA & Rank & Stochastic & Rank & DEA & Rank \\
\hline SD & 0.619 & 42 & 0.831 & 4 & 0.711 & 23 & 0.606 & 24 \\
TN & 0.641 & 38 & 0.592 & 40 & 0.703 & 27 & 0.595 & 28 \\
TX & 0.681 & 29 & 0.585 & 41 & 0.701 & 28 & 0.591 & 29 \\
UT & 0.629 & 40 & 0.627 & 32 & 0.658 & 40 & 0.553 & 40 \\
VT & 0.566 & 49 & 0.478 & 49 & 0.585 & 50 & 0.485 & 50 \\
VA & 0.779 & 8 & 0.689 & 17 & 0.821 & 6 & 0.689 & 6 \\
WA & 0.765 & 11 & 0.645 & 24 & 0.725 & 20 & 0.615 & 19 \\
WV & 0.774 & 9 & 0.670 & 22 & 0.785 & 8 & 0.664 & 8 \\
WI & 0.692 & 22 & 0.675 & 21 & 0.684 & 34 & 0.570 & 36 \\
WY & 0.723 & 17 & 0.632 & 28 & 0.875 & 5 & 0.748 & 5 \\
mean & 0.695 & & 0.653 & & 0.715 & & 0.606 & \\
\hline
\end{tabular}

TABLE 5

Correlation of State Efficiency Measures

\begin{tabular}{lcccc}
\hline & Munnell & GY & Munnell v. GY & Munnell v. GY \\
\hline $\begin{array}{l}\text { Test statistic } \\
\begin{array}{c}\text { Pearson correlation } \\
\text { coefficient }\end{array}\end{array}$ & Stochastic v. DEA & Stochastic v. DEA & Stochastic & DEA \\
$\begin{array}{l}\text { Spearman rank order } \\
\text { correlation }\end{array}$ & 0.650 & 0.994 & 0.763 & 0.354 \\
\hline
\end{tabular}

from the stochastic frontier and DEA have a Pearson correlation coefficient of 0.994 and a Spearman rank order correlation of 0.992. For the Munnell measure, the Pearson correlation coefficient is 0.650 and the Spearman's is 0.616 , both highly statistically significant.

These results suggest that while there is some question about the precise value of technical inefficiency, the two models do equally well in identifying the most and least efficient states in the manufacturing sector. If we keep the estimation technique constant and vary the capital measure, the results are a bit more mixed. If the stochastic approach is used, the measure of capital that is employed, Munnell or GY, gives very similar results, as evidenced by the Pearson coefficient (0.763) or by Spearman's (0.621). However, if DEA is the estimation method, the correlations are much weaker, though still significant at the 5 percent level for Pearson coefficient (0.354) and at the 10 percent level for the Spearman's (0.234).

In summary, if the measurement of efficiency is the main goal of the researcher, the final results are not very dependent on the choice of the capital measure or the estimation method. The relative efficiency measures will be similar regardless of which of the four possibilities is chosen. 


\subsection{Total Factor Productivity Measurement}

The Malmquist total factor productivity (TFP) indices are given in Table 6. For each state, these TFP indices are the geometric means of the annual Malmquist TFP growth for the period 1982-1996 from (7) for the DEA approach and from (14) for the stochastic frontier approach. There are four estimates for each state. Just looking at the first state, Alabama, one can see considerable variation in the TFP growth rates. The high for Alabama is 3.37 percent per year, using the Munnell capital measure and the stochastic frontier approach. The low estimate is 1.61 percent per year, using the GY measure of capital and DEA. More importantly, the rank for the state also varies considerably (from 12 to 35). A perusal of Table 6 indicates that this variation is not atypical. However, the simple means for the four possible measures of TFP change are not that different, as they vary from 2.61 percent to 3.07 percent.

The correlations in Table 7 present further evidence of the rather mixed performance of the four possible measures of Malmquist TFP indices. For the Munnell capital measure, the correlations between the stochastic approach and DEA are very low and insignificant $(0.087$ and 0.147$)$. For the GY measure of capital, the correlations are low, though significant at the 5 percent level. If the estimation method is held constant, the results are a little better. For the stochastic frontier approach, the Pearson coefficient is 0.415 , while the Spearman's is 0.273 , both significant at the 5 percent level. If DEA is the estimation method, the coefficients are higher (0.832 and 0.597) and significant at the 1 percent level. The evidence indicates that in measuring TFP growth, for a given method of estimation, the choice of the capital measure will yield similar results, but for a given capital measure, the choice of an estimation method can lead to very different results.

One of the most pronounced differences in Malmquist TFP indices and state rank occurs in New Mexico. According to the Malmquist TFP indices from the stochastic frontier models, New Mexico's average annual productivity growth (3.13 and 2.71 percent per year) is approximately the same as the average state's growth over the period (3.07 and 2.73 percent per year). However, under the DEA model, New Mexico's average annual productivity growth (12.92 and 11.86 percent per year) is well above the average state's productivity growth (2.77 and 2.61 percent per year).

Because we found that the efficiency scores are highly correlated, we focus on measures of technical change to see why the stochastic frontier and DEA models yield such different results. Figure 3 shows the year-to-year change in technology in the state of New Mexico using each capital measure and estimation method. Time period 1 is 1982/1983; time period 2 is 1983/1984, and so on. We note that the two technical change measures from (13) under the stochastic frontier model are very close to each other and are very stable from year to year. In contrast, the two technical change measures from the second term on the right side of (7) under the DEA model are quite volatile from year to year. This is especially true for periods 11 (1992/1993) through 14 (1995/1996). 
It is well known that the DEA model is very sensitive to extreme observations. Therefore, to see whether extreme observations might be influencing the DEA estimates, we look at a scatter plot of the output-capital ratio $(Y / K)$ and the labor-capital ratio $(L / K)$. (See Simar, 2003, for a method of detecting extreme values in data sets with multipleoutputs and multiple-inputs.) Figures 4 and 5 contain these scatter plots for the Munnell and GY capital measures, respectively. In each figure, we observe extreme data points. These four extreme data points with the highest levels of $Y / K$ (of about 1.5 and higher) using the lowest values of $L / K$ (of about 27 to 30) are input-output observations on the state of New Mexico. New Mexico is a relatively small state with a manufacturing sector dominated by one large firm, Intel (it accounts for about 75 percent of all manufacturing output in the state). Intel's output soared in the early 1990s following a capital expansion. The combination of a very high-valued output and low labor requirements resulted in the extreme values for New Mexico in Figures 4 and 5. The presence of these extreme data points may be the cause of the unstable results in the DEA model. Thus, we suggest that the researcher examine the data for extreme values or outliers prior to choosing the estimation model.

\section{TABLE 6}

State Total Factor Productivity in Manufacturing

\begin{tabular}{lcrrrrrrr}
\hline & & \multicolumn{3}{c}{ Munnell Capital Measure } & \multicolumn{3}{c}{ GY Capital Measure } \\
\cline { 3 - 6 } State & Stochastic & Rank & \multicolumn{1}{c}{ DEA } & Rank & Stochastic & Rank & DEA & Rank \\
\hline AL & 1.0337 & 12 & 1.0243 & 25 & 1.0261 & 30 & 1.0161 & 35 \\
AK & 1.0221 & 48 & 1.0107 & 43 & 1.0223 & 45 & 1.0062 & 48 \\
AZ & 1.0338 & 11 & 1.0646 & 2 & 1.0339 & 3 & 1.0578 & 2 \\
AR & 1.0344 & 8 & 1.0184 & 33 & 1.0229 & 42 & 1.0158 & 37 \\
CA & 1.0315 & 23 & 1.0164 & 35 & 1.0328 & 6 & 1.0326 & 15 \\
CO & 1.0313 & 27 & 1.0348 & 15 & 1.0303 & 10 & 1.0239 & 26 \\
CT & 1.0316 & 22 & 1.0007 & 50 & 1.0338 & 4 & 1.0355 & 9 \\
DE & 1.0219 & 49 & 1.0161 & 36 & 1.0247 & 40 & 1.0173 & 33 \\
FL & 1.0333 & 14 & 1.0197 & 31 & 1.0300 & 12 & 1.0119 & 43 \\
GA & 1.0324 & 16 & 1.0152 & 37 & 1.0225 & 43 & 1.0133 & 41 \\
HI & 1.0283 & 40 & 1.0243 & 26 & 1.0260 & 31 & 1.0142 & 39 \\
ID & 1.0320 & 20 & 1.0466 & 4 & 1.0292 & 17 & 1.0415 & 5 \\
IL & 1.0323 & 18 & 1.0299 & 20 & 1.0313 & 8 & 1.0264 & 22 \\
IN & 1.0304 & 30 & 1.0339 & 17 & 1.0297 & 15 & 1.0321 & 17 \\
IA & 1.0294 & 36 & 1.0336 & 18 & 1.0259 & 32 & 1.0338 & 12 \\
KS & 1.0312 & 29 & 1.0047 & 46 & 1.0252 & 37 & 1.0065 & 46 \\
KY & 1.0236 & 47 & 1.0241 & 29 & 1.0187 & 49 & 1.0201 & 29 \\
LA & 1.0199 & 50 & 1.0394 & 10 & 1.0184 & 50 & 1.0363 & 8 \\
ME & 1.0346 & 7 & 1.0293 & 21 & 1.0282 & 25 & 1.0116 & 44 \\
MD & 1.0313 & 24 & 1.0138 & 38 & 1.0288 & 20 & 1.0154 & 38 \\
MA & 1.0324 & 17 & 1.0096 & 44 & 1.0335 & 5 & 1.0325 & 16 \\
MI & 1.0264 & 46 & 1.0242 & 28 & 1.0300 & 11 & 1.0188 & 31
\end{tabular}




\begin{tabular}{lcrrrrrrr}
\hline & \multicolumn{9}{c}{ Munnell Capital Measure } & \multicolumn{3}{c}{ GY Capital Measure } \\
State & Stochastic & Rank & \multicolumn{1}{c}{ DEA } & Rank & Stochastic & Rank & DEA & Rank \\
\hline MN & 1.0300 & 31 & 1.0131 & 42 & 1.0299 & 13 & 1.0189 & 30 \\
\hline MS & 1.0359 & 2 & 1.0202 & 30 & 1.0224 & 44 & 1.0221 & 28 \\
MO & 1.0284 & 38 & 1.0171 & 34 & 1.0257 & 33 & 1.0237 & 27 \\
MT & 1.0296 & 34 & 1.0193 & 32 & 1.0250 & 38 & 1.0171 & 34 \\
NE & 1.0333 & 13 & 1.0331 & 19 & 1.0248 & 39 & 1.0161 & 36 \\
NV & 1.0313 & 26 & 1.0382 & 11 & 1.0254 & 34 & 1.0064 & 47 \\
NH & 1.0338 & 10 & 1.0461 & 5 & 1.0339 & 2 & 1.0541 & 3 \\
NJ & 1.0292 & 37 & 1.0134 & 40 & 1.0298 & 14 & 1.0342 & 11 \\
NM & 1.0313 & 28 & 1.1292 & 1 & 1.0271 & 27 & 1.1186 & 1 \\
NY & 1.0279 & 42 & 1.0015 & 49 & 1.0284 & 24 & 1.0273 & 20 \\
NC & 1.0317 & 21 & 1.0137 & 39 & 1.0204 & 47 & 1.0080 & 45 \\
ND & 1.0354 & 3 & 1.0280 & 24 & 1.0254 & 35 & 1.0253 & 24 \\
OH & 1.0284 & 39 & 1.0288 & 23 & 1.0291 & 18 & 1.0306 & 18 \\
OK & 1.0295 & 35 & 1.0426 & 9 & 1.0289 & 19 & 1.0413 & 6 \\
OR & 1.0299 & 32 & 1.0604 & 3 & 1.0280 & 26 & 1.0523 & 4 \\
PA & 1.0322 & 19 & 1.0350 & 14 & 1.0318 & 7 & 1.0350 & 10 \\
RI & 1.0368 & 1 & 1.0029 & 48 & 1.0305 & 9 & 1.0125 & 42 \\
SC & 1.0354 & 4 & 1.0437 & 7 & 1.0269 & 28 & 1.0274 & 19 \\
SD & 1.0353 & 5 & 1.0343 & 16 & 1.0240 & 41 & 1.0174 & 32 \\
TN & 1.0330 & 15 & 1.0132 & 41 & 1.0261 & 29 & 1.0141 & 40 \\
TX & 1.0299 & 33 & 1.0376 & 12 & 1.0287 & 21 & 1.0326 & 14 \\
UT & 1.0338 & 9 & 1.0438 & 6 & 1.0287 & 22 & 1.0270 & 21 \\
VT & 1.0351 & 6 & 1.0288 & 22 & 1.0339 & 1 & 1.0244 & 25 \\
VA & 1.0280 & 41 & 1.0079 & 45 & 1.0219 & 46 & 1.0050 & 50 \\
WA & 1.0278 & 43 & 1.0034 & 47 & 1.0292 & 16 & 1.0052 & 49 \\
WV & 1.0268 & 44 & 1.0358 & 13 & 1.0254 & 36 & 1.0365 & 7 \\
WI & 1.0313 & 25 & 1.0242 & 27 & 1.0287 & 23 & 1.0261 & 23 \\
WY & 1.0264 & 45 & 1.0430 & 8 & 1.0194 & 48 & 1.0333 & 13 \\
mean & 1.0307 & & 1.0277 & & 1.0273 & & 1.0261 & \\
\hline & & & & & & & &
\end{tabular}

TABLE 7

Correlation of State TFP Measures

\begin{tabular}{lcccc}
\hline & Munnell & GY & Munnell v. GY & Munnell v. GY \\
\hline $\begin{array}{l}\text { Test statistic } \\
\begin{array}{l}\text { Pearson correlation } \\
\text { coefficient }\end{array}\end{array}$ & Stochastic v. DEA & Stochastic v. DEA & Stochastic & DEA \\
$\begin{array}{l}\text { Spearman rank order } \\
\text { correlation }\end{array}$ & 0.087 & 0.285 & 0.415 & 0.832 \\
\hline
\end{tabular}




\section{FIGURE 3}

New Mexico - DEA v. Stochastic

(GY Capital Measure - Square v. Diamond;

Munnell Capital Measure - Triangle v. Star)

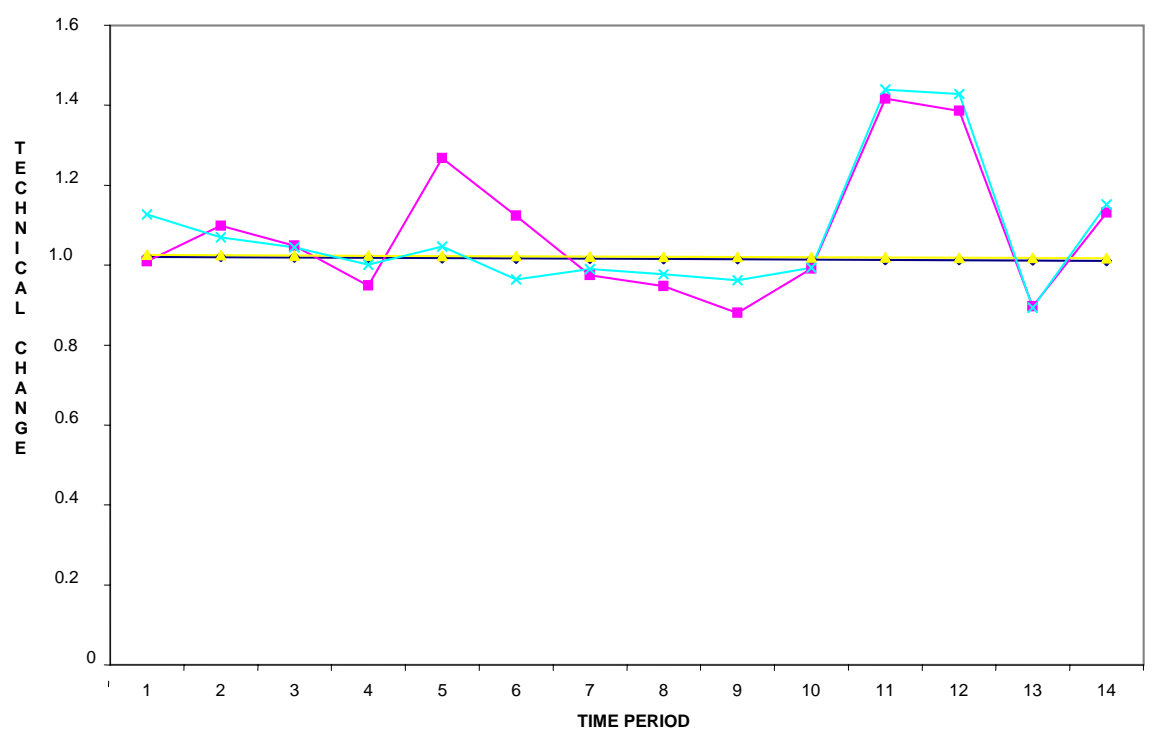

FIGURE 4

1982-1996 Data (Munnell Capital Measure)

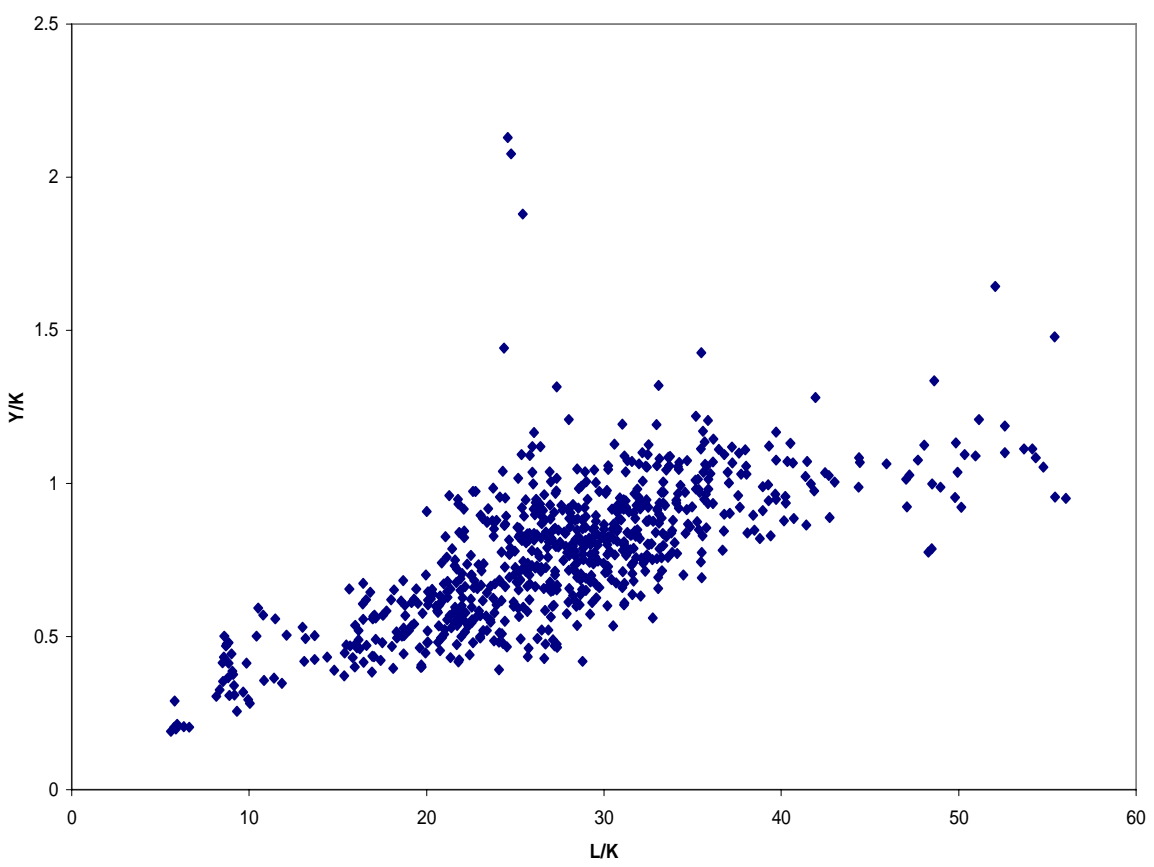


FIGURE 5

1982-1996 Data (GY Capital Measure)

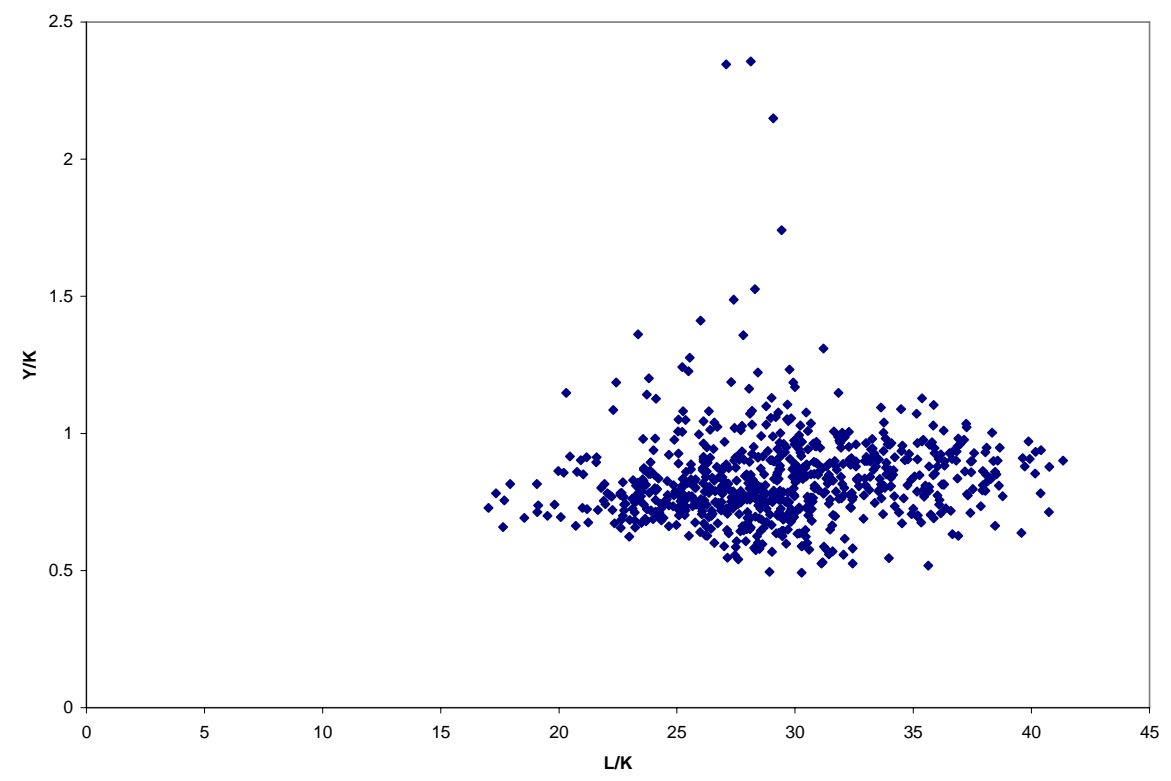

\section{SUMMARY AND CONCLUSIONS}

In this paper, we consider two different measures of capital stock as developed by Munnell (1990) and by Garofalo and Yamarik (2002). In addition, we consider two methods of measuring efficiency and TFP growth: the stochastic frontier and DEA models. A researcher considering the measurement of capital and the methods of estimation that are employed in this paper will have a choice of four possible approaches for estimating efficiency or TFP growth. Given that the true measure of capital is unknown and that the actual levels of efficiency and TFP growth are also unknown, is it possible to say anything about which capital measures or estimation methods are the best to use?

Based on state-level data for the period 1982-1996, we found that while there is a difference in the magnitude of the technical efficiency estimates from the four approaches, the estimates are strongly correlated. For example, based on the GY capital measure, the efficiency estimates from the stochastic frontier and DEA have a Pearson correlation coefficient of 0.994 and a Spearman rank order correlation of 0.992 . For the Munnell measure, the Pearson correlation coefficient is 0.650 and the Spearman's is 0.616 , both highly statistically significant.

So, if the measurement of efficiency is the main goal of the researcher, the estimates of technical efficiency are not very sensitive to the choice of the capital measure or the 
estimation method. The relative efficiency measures are similar regardless of which of the four possibilities is chosen.

Our results indicate a rather mixed performance of the four possible measures of TFP growth. The measures of TFP growth are significantly correlated when using the same model but different measures of capital. For the stochastic frontier approach, the Pearson coefficient between the measures of TFP growth based on the Munnell and GY measures of capital is 0.415 , while the Spearman's is 0.273 , both significant at the 5 percent level. If DEA is the estimation method, the correlation coefficients are even higher ( 0.832 and 0.597 ) and significant at the 1 percent level. However, different estimation methods can lead to very different results when using a particular measure of capital. For the Munnell capital measure, the correlations of the measures of TFP growth between the stochastic approach and DEA models are very low and insignificant (0.087 and 0.147). For the GY measure of capital, the correlations are low, though significant at the 5 percent level.

We investigated why the stochastic frontier and DEA models yielded such different results for TFP growth. The main reason appeared to be unstable DEA estimates of technical change. After examining the data, we concluded that the presence of extreme data points may be the cause of the unstable results in the DEA model. Thus, we suggest that the researcher examine the data for extreme values or outliers prior to choosing the estimation model. Clearly, the choice of the sample will influence the results.

\section{REFERENCES}

Aaberg, R.Y., 1973. "Productivity Differences in Swedish Manufacturing," Regional Science and Urban Economics 3(2), 131-156.

Battese, G.E. and T.J. Coelli, 1992. "Frontier Production Functions, Technical Efficiency and Panel Data: With Application to Paddy Farmers in India," Journal of Productivity Analysis 3(1-2), 153-169.

Caves, D.W., L.R. Christensen, and W.E. Diewert, 1982. "The Economic Theory of Index Numbers and the Measurement of Input, Output, and Productivity," Econometrica 50 (6), 1393-1414.

Coelli, T.J., 1996. A Guide to Frontier Version 4.1: A Computer Program for Stochastic Production and Cost Function Estimation," CEPA Working Paper 96/07, Centre for Efficiency and Productivity Analysis. Armidale: University of New England.

Coelli, T., D.S.P. Rao, and G.E. Battese, 1999. An Introduction to Efficiency and Productivity Analysis. Kluwer Academic Publishers: Boston.

Domazlicky, B.R. and W.L. Weber, 1997. "Total Factor Productivity in the Contiguous United States, 1977-86," Journal of Regional Science 37(2), 213-233. , 2006. "The Measurement of Capital and the Measurement of Productivity Growth and Efficiency in State Manufacturing," International Regional Science Review 29(2), 115-134.

Färe, R., S. Grosskopf, and C.A.K. Lovell, 1994. Production Frontiers. Cambridge University Press: Cambridge. 
Färe, R., S. Grosskopf, and C.A. Pasurka, 2001. "Accounting for Air Pollution Emissions in Measures of State Manufacturing Productivity Growth," Journal of Regional Science 41(3), 381-410.

Färe, R., S. Grosskopf, and P. Roos, 1998. "Malmquist Productivity Indexes: A Survey of Theory and Practice," in R. Färe, S. Grosskopf, and R.R. Russell (eds.), Index Numbers: Essays in Honor of Stan Malmquist Kluwer Academic Publishers: Boston.

Farrell, M.J., 1957. "The Measurement of Productive Efficiency," Journal of the Royal Statistical Society A 120, 253-282.

Garofalo, G. and S. Yamarik, 2002. "Regional Convergence: Evidence from a New State-By-State Capital Stock Series," Review of Economics and Statistics 84(2), 316323.

Gerking, S., 1994. "Measuring Productivity Growth in U.S. Regions: A Survey," International Regional Science Review 16(1-2), 155-185.

Holtz-Eakin, D., 1994. "Public Sector Capital and the Productivity Puzzle," Review of Economics and Statistics 76(1), 12-21.

Hulten, C.R. and R.M. Schwab, 1984. "Regional Productivity Growth in U.S. Manufacturing, 1951-78," American Economic Review 74(1), 152-162.

Kodde, D.A. and F.C. Palm, 1986. "Wald Criteria for Jointly Testing Equality and Inequality Restrictions," Econometrica 54(5), 1243-1248.

Kumbhakar, S.C. and C.A.K. Lovell, 2000. Stochastic Frontier Analysis. Cambridge University Press: Cambridge, U.K.

Morrison, C.J. and A.E. Schwartz, 1996. "State Infrastructure and Productive Performance," American Economic Review 86(5), 1095-1111.

Mullen, J.K. and M. Williams, 1990. "Explaining Total Factor Productivity Differentials in Urban Manufacturing," Journal of Urban Economics 28(1), 103-123.

Munnell, A., 1990. "How Does Public Infrastructure Affect Regional Economic Performance?" in Munnell (ed.), Is There a Shortfall in Public Capital Investment? Federal Reserve Bank of Boston: Boston, MA.

Simar, L., 2003. "Detecting Outliers in Frontier Models: A Simple Approach," Journal of Productivity Analysis 20(3), 391-424.

Weber, W. L. and B. R. Domazlicky, 1999. "Total Factor Productivity Growth in Manufacturing: A Regional Approach Using Linear Programming," Regional Science and Urban Economics 29(1), 105-122.

Williams, R. and R. Moomaw, 1989. "Capital and Labor Efficiencies: A Regional Analysis," Urban Studies 26(4), 573-585. 